\title{
Propofol Safety in Bronchoscopy: Prospective Randomized Trial Using Transcutaneous Carbon Dioxide Tension Monitoring
}

\author{
Uri Carmi a, c Mordechai R. Kramer ${ }^{b, c}$ Dmitry Zemtzov ${ }^{a, c}$ Dror Rosengarten ${ }^{b, c}$ \\ Oren Fruchter ${ }^{\mathrm{b}, \mathrm{c}}$
}

${ }^{a}$ Department of Anesthesia and ${ }^{\mathrm{b}}$ The Pulmonary Division, Rabin Medical Center, Petach Tikva, and

'Sackler Faculty of Medicine, Tel Aviv University, Tel Aviv, Israel

\section{Key Words}

Bronchoscopy $\cdot$ Carbon dioxide $\cdot$ Monitoring

\begin{abstract}
Background: Midazolam is commonly used for sedation during flexible bronchoscopy because of its relatively wide therapeutic window. Recently, sedation with propofol for bronchoscopy has gained popularity, although concern has been raised regarding its potential ability to induce severe respiratory depression. Objectives: The aim of this study was to evaluate the safety of sedation under midazolam + alfentanil compared to propofol. Methods: We conducted a prospective randomized trial using continuous transcutaneous carbon dioxide tension monitoring. The study group included 115 patients undergoing bronchoscopy, prospectively randomized to receive sedation with either midazolam + alfentanil $(n=59)$ or propofol $(n=56)$. Results: Intra-procedural carbon dioxide tension values were higher in the midazolam + alfentanil group than in the propofol group (maximum 53.72 vs. $49.49 \mathrm{~mm} \mathrm{Hg}$, mean 46.78 vs. $43.78 \mathrm{~mm} \mathrm{Hg}$ ), but the differences did not reach statistical significance $(p=0.149$ and 0.193 , respectively). Carbon dioxide tension values were significantly higher in the midazolam + alfentanil group than
\end{abstract}

in the propofol group at 5 and $10 \mathrm{~min}$ following procedure (51.7 vs. $49.3 \mathrm{~mm} \mathrm{Hg}, p=0.026$, and 50.8 vs. $42.7 \mathrm{~mm} \mathrm{Hg}, \mathrm{p}<$ 0.01 , respectively), and significantly more patients in the midazolam + alfentanil group needed oxygen supplementation or airway support (24 vs. 8 patients, respectively). Conclusion: Midazolam + alfentanil and propofol are equally safe for sedation during bronchoscopy. Sedation with propofol, using small boluses at short intervals, does not cause excessive respiratory drive depression and represents an excellent alternative to traditional sedation agents.

Copyright $\odot 2011$ S. Karger AG, Basel

\section{Introduction}

Flexible fiberoptic bronchoscopy (FFB) is commonly used for the diagnosis and management of a variety of lung diseases. Although it may be performed with local anesthesia only, the addition of sedation can facilitate the examination of the tracheobronchial tree, lessen untoward physiologic responses to airway manipulation, diminish patient movement, and improve patient safety and comfort [1-4].

\section{KARGER}

Fax +4161306 1234

E-Mail karger@karger.ch

www.karger.com
C 2011 S. Karger AG, Basel

0025-7931/11/0826-0515\$38.00/0

Accessible online at:

www.karger.com/res
Prof. Mordechai R. Kramer, MD

Pulmonary Institute

Rabin Medical Center, Beilinson Hospital

Petach Tikva 49100 (Israel)

Tel. +972 3937 7221, E-Mail kremerm@ @lalit.org.il 


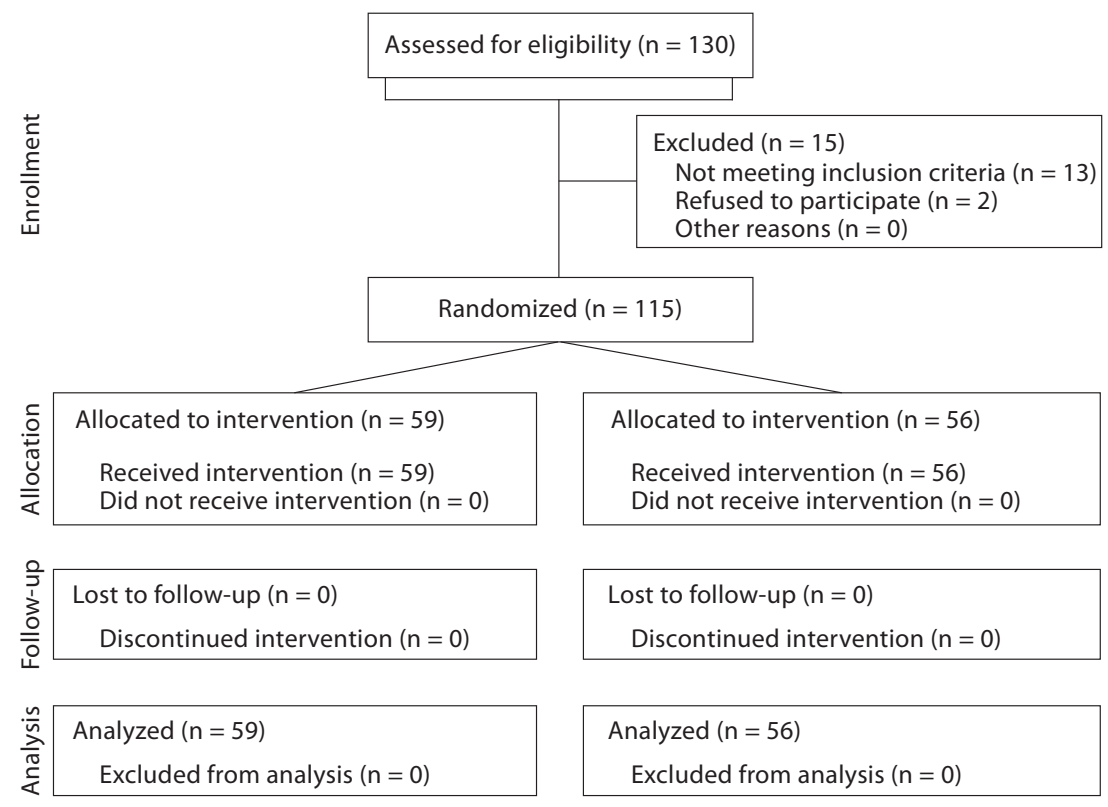

Fig. 1. Study design and allocation of study patients.

Midazolam, with or without a short-acting opiate, is the traditional choice for sedation in FFB because of its wide therapeutic window, its relatively short duration of action and the availability of an antidote - flumazenil. Recently, sedation with propofol for bronchoscopy has gained popularity, although concern has been raised regarding its potential ability to induce severe respiratory depression $[5,6]$. Randomized studies comparing propofol and midazolam sedation during FFB suggested a similar efficacy but faster onset of action and a more rapid patient recovery for propofol [7-10]. However, in all of them, the safety of the sedatives was mainly assessed using pulse oximetry.

Pulse oximetry measures the oxygen level in blood, but it cannot detect carbon dioxide tension, an indicator of the ventilatory status $[11,12]$. Bronchoscopy performed under conscious sedation without supplemental oxygen can rapidly lead to oxygen desaturation. Therefore, most centers routinely offer oxygen supplementation to patients during the procedure [13]. In such situations, owing to the sigmoidal shape of the oxygen dissociation curve, the alveolar carbon dioxide tension has to increase further before significant hypoxemia is manifested [14]. The British Thoracic Society guidelines recommend that oxygen supplementation be used to achieve an oxygen saturation $\left(\mathrm{SpO}_{2}\right)$ of at least $90 \%$ to reduce the risk of significant arrhythmias [2]. At the same time, they caution that clinicians should be alert to signs of respiratory failure in patients on oxygen supplementation, who may have normal oximetry readings despite the development of hypoventilation and carbon dioxide retention [2].

Cutaneous carbon dioxide tension $\left(\mathrm{PcCO}_{2}\right)$ can be efficiently measured with a digital earlobe sensor [15]. Studies report a good correlation of $\mathrm{PcCO}_{2}$ values with arterial blood gas measurements [16-19]. Similar to medical thoracoscopy and colonoscopy, bronchoscopy is also associated with an increase in $\mathrm{PcCO}_{2}[17,19,20]$.

Prompted by these findings and with reports of a high tendency of propofol to reduce the respiratory drive [6], we sought to compare the safety of sedation with propofol or midazolam + alfentanil during FFB by measuring $\mathrm{PcCO}_{2}$ with a single earlobe sensor.

\section{Methods}

A prospective randomized study design was used (fig. 1). The study group consisted of 115 patients scheduled for FFB under lo$\mathrm{cal}$ anesthesia with sedation at a tertiary medical center. All sub- 
Table 1. Background and clinical characteristics of 115 patients undergoing bronchoscopy

\begin{tabular}{lccc}
\hline Characteristics & Midazolam/alfentanil & Propofol & p value \\
\hline Patients & 59 & 56 & $30 / 26$ \\
Males/females & $37 / 22$ & $62 \pm 16(25-88)$ & 0.612 \\
Mean age \pm SD, years & $63.5 \pm 14.3(24-88)$ & & \\
Procedure & & 48 & \\
Bronchoalveolar lavage & 47 & 4 & \\
Endobronchial biopsy & 18 & 29 & \\
Transbronchial needle aspiration & 5 & 7 & \\
Transbronchial biopsy & 21 & 2 & \\
Mechanical debridment/dilatation & 7 & 16 & 0.44 \\
Bronchial brushings & 12 & $36.7 \pm 6.4$ \\
Brachiotherapy & 1 & $98 \pm 1.6$ \\
Hemodynamics before procedure & 17 & $76.8 \pm 16.9$ & 0.777 \\
Duration of procedure, min & $37.6 \pm 5.3$ & $140.9 \pm 19$ & 0.141 \\
Mean PcCO \pm SD, mm Hg & $98 \pm 1.9$ & $80.5 \pm 13.6$ & 0.625 \\
Mean SpO \pm SD, mm Hg & $72.8 \pm 11.7$ & 0.11 \\
Mean DBP \pm SD, mm Hg & $142.8 \pm 22.6$ & & \\
Mean SBP \pm SD, mm Hg & $76.1 \pm 15.3$ & & \\
Mean HR \pm SD, bpm & & & \\
\hline
\end{tabular}

Figures in parentheses are ranges. $\mathrm{DBP}=$ Diastolic blood pressure; $\mathrm{SBP}=$ systolic blood pressure; $\mathrm{HR}=$ heart rate.

jects provided written informed consent for bronchoscopy, and the study has been approved by the local ethics committee (ClinicalTrials.gov, identifier: NCT01289327). Exclusion criteria for the study were inability or refusal to provide informed consent, age $<18$ years, bronchoscopy through an artificial airway such as endotracheal tube or tracheostomy, use of laser during the procedure, and allergy to one of the sedative drugs.

Patients were randomly assigned by a computer before the procedure to receive sedation with midazolam + alfentanil or propofol. Local anesthesia was induced by application of $2 \% \mathrm{li}-$ docaine to the oropharynx to all patients only at the beginning of the procedure. Sedation was started with intravenous injection of a bolus of 2-4 mg midazolam and $0.5 \mathrm{mg}$ alfentanil or 20-50 mg propofol. It was maintained with intermittent boluses of 1-3 mg intravenous midazolam or $0.5 \mathrm{mg}$ intravenous alfentanil, according to clinical judgment, or with boluses of 10-20 mg intravenous propofol, administered at short intervals (about $2 \mathrm{~min}$ ) or according to clinical judgment. One of the authors (U.C. or D.Z.) was present throughout each procedure and was in charge of administering the sedation and monitoring the patient.

In all cases, monitoring included continuous electrocardiography, pulse oximetry and automated noninvasive blood pressure recordings every $5 \mathrm{~min}$. In addition, $\mathrm{PcCO}_{2}$ was measured with a cutaneous digital sensor (Sentec AG, Therwil, Switzerland) that was placed on the earlobe prior to the procedure. It was removed when the patient left the bronchoscopy suite.

During the procedure, all patients received supplemental nasal oxygen at $2-5 \mathrm{l} / \mathrm{min}$. Significant hypoxemia, defined as func- tional $\mathrm{SpO}_{2}$ of $90 \%$, was treated initially with jaw support. If it lasted more than a few seconds, a nasal/oropharyngeal tube was inserted or supplemental oxygen was delivered via face mask at $10 \mathrm{l} / \mathrm{min}$. The duration of bronchoscopy was calculated from the administration of sedation until the flexible bronchoscope was removed from the tracheobronchial tree.

A questionnaire evaluating pain and discomfort by means of a visual analogue scale ( $0=$ no bother, $10=$ intolerable $)$ and a multiple choice questionnaire about the willingness to repeat the procedure was completed by the patient after awaking at the end of the procedure.

\section{Statistical Analysis}

The null hypothesis (H0) was defined as there being no difference in peak transcutaneous carbon dioxide tension between the two intervention groups. Sample size determination (unpaired $t$ test, power 0.99 , two-sided type I error 0.05 , or unpaired t test, power 0.95 , two-sided type I error 0.01 ) was performed with an estimated SD of $6 \mathrm{~mm} \mathrm{Hg}$ for the mean difference of $\mathrm{PcCO}_{2}$ [20], and a difference of at least $5 \mathrm{~mm} \mathrm{Hg}$ between the two intervention groups. Accordingly, at least 56 subjects were needed in each group for $\mathrm{H} 0$ rejection. Statistical analyses were carried out by $\chi^{2}$ test and Student's t test, as appropriate; $p$ values $\leq 0.05$ were considered significant. Data were analyzed using SPSS software, version 14.0 . 
Table 2. Monitoring values during and after bronchoscopy in 115 study patients

\begin{tabular}{|c|c|c|c|}
\hline Parameters & Midazolam/alfentanil & Propofol & $\mathrm{p}$ value \\
\hline \multicolumn{4}{|l|}{ During FFB } \\
\hline \multicolumn{4}{|l|}{$\mathrm{PcCO}_{2}, \mathrm{~mm} \mathrm{Hg}$} \\
\hline Maximum & $53.7 \pm 14.2$ & $49.4 \pm 11.1$ & 0.129 \\
\hline Mean & $46.7 \pm 10.1$ & $43.78 \pm 7.3$ & 0.148 \\
\hline \multicolumn{4}{|l|}{$\mathrm{PcCO}_{2}$ delta $^{1}, \mathrm{~mm} \mathrm{Hg}$} \\
\hline Maximum & $16 \pm 11.9$ & $13.2 \pm 8.3$ & 0.149 \\
\hline Mean & $9.1 \pm 7.3$ & $7.5 \pm 5.2$ & 0.193 \\
\hline \multicolumn{4}{|l|}{$\mathrm{SpO}_{2}, \mathrm{~mm} \mathrm{Hg}$} \\
\hline Minimum & $88.7 \pm 3.6$ & $88.1 \pm 5.1$ & 0.502 \\
\hline Mean & $95.5 \pm 2.6$ & $95.4 \pm 2.3$ & 0.774 \\
\hline \multicolumn{4}{|l|}{$\mathrm{SpO}_{2}$ delta $^{1}, \mathrm{~mm} \mathrm{Hg}$} \\
\hline Maximum & $9.8 \pm 3.4$ & $10.4 \pm 5.4$ & 0.44 \\
\hline Mean & $2.9 \pm 2.3$ & $3.1 \pm 2.3$ & 0.597 \\
\hline $\mathrm{DBP}^{2}, \mathrm{~mm} \mathrm{Hg}$ & $74 \pm 9.9$ & $70.5 \pm 11.9$ & 0.088 \\
\hline $\mathrm{SBP}^{2}, \mathrm{~mm} \mathrm{Hg}$ & $139.4 \pm 20.5$ & $128.3 \pm 28.2$ & 0.053 \\
\hline $\mathrm{HR}^{2}, \mathrm{bpm}$ & $78.5 \pm 11.7$ & $82.4 \pm 13.1$ & 0.093 \\
\hline Oxygen supplementation, $\mathrm{n}(\%)$ & $18(30.5)$ & $6(10.7)$ & 0.0195 \\
\hline Nasal/oropharyngeal tube insertion, $\mathrm{n}(\%)$ & $6(10.1)$ & $2(3.6)$ & 0.2725 \\
\hline \multicolumn{4}{|l|}{ After FFB } \\
\hline $\mathrm{PcCO}_{2}$ at $0 \mathrm{~min}, \mathrm{~mm} \mathrm{Hg}$ & $51.5 \pm 2.1$ & $49.3 \pm 2.1$ & 0.318 \\
\hline $\mathrm{PcCO}_{2}$ at $5 \mathrm{~min}, \mathrm{~mm} \mathrm{Hg}$ & $51.7 \pm 12.8$ & $47.2 \pm 7.9$ & 0.026 \\
\hline $\mathrm{PcCO}_{2}$ at $10 \mathrm{~min}, \mathrm{~mm} \mathrm{Hg}$ & $50.8 \pm 11.7$ & $42.7 \pm 6.9$ & $<0.01$ \\
\hline \multicolumn{4}{|c|}{$\begin{array}{l}\text { All values are means } \pm \mathrm{SD} \text {, unless otherwise indicated. } \mathrm{DBP}=\text { Diastolic blood pressure; } \mathrm{SBP}=\text { systolic blood } \\
\text { pressure; } \mathrm{HR}=\text { heart rate. } \mathrm{PcCO}_{2}, \mathrm{SpO}_{2}, \mathrm{HR} \text { : measured every } 4 \mathrm{~s} \text {. Blood pressure: measured every } 5 \text { min. } \\
{ }^{1} \text { Difference from baseline. } \\
{ }^{2} \text { Mean of all values during the FFB. }\end{array}$} \\
\hline
\end{tabular}

\section{Results}

Fifty-six patients were sedated with midazolam + alfentanil and 56 with propofol. Table 1 shows the background and clinical characteristics of the two groups. There were no significant between-group differences in demographics and type of bronchoscopic procedure, or in hemodynamic parameters, $\mathrm{SpO}_{2}$ and $\mathrm{PcCO}_{2}$ at baseline. The mean total dose of propofol administered was $208 \mathrm{mg}$ (range 30-530); the mean rate (total dose/duration of procedure) was $13.4 \mathrm{mg} / \mathrm{min}$ (mean of 10 boluses). The mean total dose of midazolam was $6.8 \mathrm{mg}$ (range 2.5-17) and of alfentanil $0.75 \mathrm{mg}$ (range 0.5-1.5); mean rates were 0.53 and $0.06 \mathrm{mg} / \mathrm{min}$, respectively (mean of 3 boluses of midazolam).

Table 2 presents the monitoring values during FFB. For $\mathrm{SpO}_{2}$ and $\mathrm{PcCO}_{2}$, we also calculated the difference between the measured values and the values recorded before the procedure. Neither group showed a signifi- cant rise in heart rate during FFB relative to the presedation values. There was no significant difference between the groups in systolic and diastolic blood pressure measurements. $\mathrm{PcCO}_{2}$ values during the procedure, both maximum and mean, were higher in the midazolam + alfentanil group (maximum 53.72, mean 46.78 $\mathrm{mm} \mathrm{Hg}$ ) than in the propofol group (maximum 49.49, mean $43.78 \mathrm{~mm} \mathrm{Hg}$ ), but the differences did not reach statistical significance $(\mathrm{p}=0.149$ and 0.193 , respectively). There was no significant between-group difference in maximum or mean $\mathrm{SpO}_{2}$ during the procedure. Figure 2 presents the $\mathrm{PcCO}_{2}$ tension level during the procedure at a time scale. There was no difference between the groups during the procedure. The midazolam + alfentanil group needed three times more oxygen supplementation and/or airway support than the propofol group -30 vs. $10.7 \%(\mathrm{p}=0.0195)$ and 10.1 vs. $3.6 \%(\mathrm{p}=$ 0.2725 ) of patients, for oxygen supplementation and airway support, respectively. 
Fig. 2. Transcutaneous carbon dioxide tension monitoring during bronchoscopy in patients sedated with midazolam + alfentanil versus propofol. The average $\mathrm{PcCO}_{2}$ level is shown for each group at the same time during the first $20 \mathrm{~min}$. There is no $\mathrm{PcCO}_{2}$ level difference between the groups at any time during the FFB. Note: percent patients with FBB time $<20$ min were 68 and 63 for the midazolam + alfentanil and propofol groups, respectively.

Fig. 3. Transcutaneous carbon dioxide tension monitoring during recovery following bronchoscopy in patients sedated with midazolam + alfentanil versus propofol. The average $\mathrm{PcCO}_{2}$ level is shown for each group at the same time during the first 10 min after the end of FBB. There is a $\mathrm{PcCO}_{2}$ level difference between the groups at 5 and $10 \mathrm{~min}$.
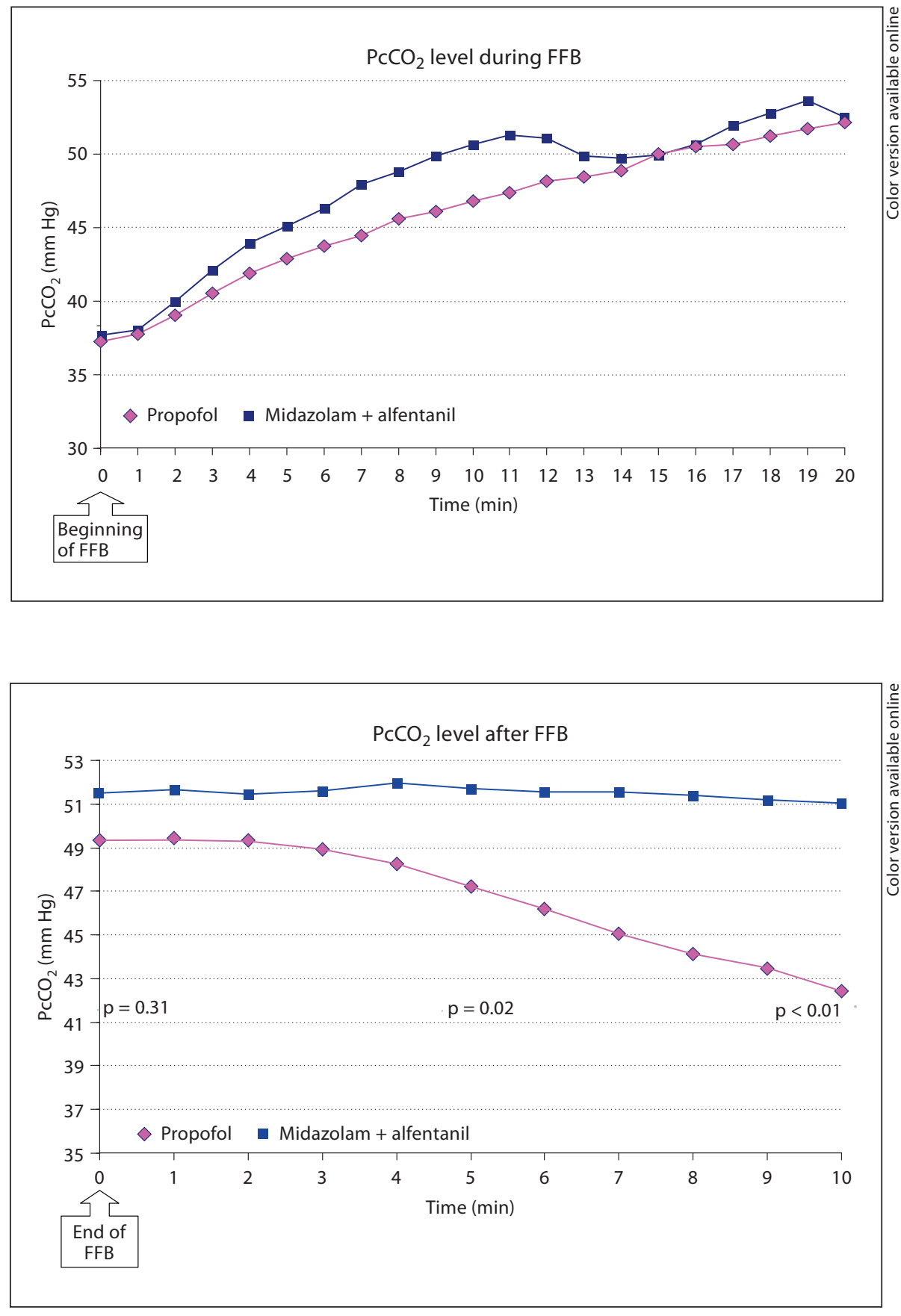

There was a significant difference between the groups in carbon dioxide tension values both at 5 and $10 \mathrm{~min}$ after the procedure finished.

Figure 3 clearly shows that carbon dioxide tension in the propofol group declined much faster toward baseline.

None of the patients in either group complained of any pain or an unpleasant feeling during the procedure. All patients reported that they would do the procedure again, if necessary.

There were no adverse events or adverse clinical consequences associated with the procedure. None of the patients were intubated, had a severe arrhythmia or exhibited cognitive decline after the procedure. 


\section{Conclusions}

The present study compared the safety of midazolam + alfentanil versus propofol for sedation during FFB. Importantly, pulse oximetry was combined with $\mathrm{PcCO}_{2}$ measurements to monitor the ventilatory status during the procedure.

The results showed no difference between the study groups in respiratory depression during FFB. Furthermore, fewer patients in the group sedated by propofol needed airway support or oxygen supplementation. This finding may be attributable to the higher number of boluses of propofol than of midazolam administered during the procedures (mean of 10 vs. 3), so there were lower peaks in blood drug concentration in the propofol group. Another explanation may be the combination of benzodiazepine with an opiate that can cause respiratory depression [21].

In the present study, there was no significant betweengroup difference in $\mathrm{SpO}_{2}$ during the entire procedure. However, unlike the carbon dioxide level, which was measured in an observational fashion, $\mathrm{SpO}_{2}$ was used to guide the treatment. In the midazolam + alfentanil group, there were more events of significant hypoxemia treated by nasal/oropharyngeal tube insertion or supplemental face mask oxygen.

The usual hemodynamic response to FFB is an increase in heart rate and blood pressure [22-24]. These changes are of little consequence in patients with normal cardiovascular function. However, in patients with coronary artery disease or in elderly patients with accompanying lung disease, who account for a large proportion of the population who undergo FFB, they may have impor- tant repercussions. Surprisingly, in the present study, neither sedation group showed a significant rise in heart rate or blood pressure. Indeed, a nonsignificant decrease in blood pressure was observed in the propofol group. The most likely explanation for this finding is the sedation protocol: the doses of both midazolam and alfentanil in our study were higher than those employed in similar studies [21]. The association of the higher dose with stable heart rate and blood pressure is supported by an earlier study from our institute on the hemodynamic response to FFB [25]. The stable hemodynamics may also be related to the recent wide use of $\beta$ blockers for patients with coronary artery disease or high blood pressure.

Propofol provides faster neuropsychometric recovery [10]. This study shows that it also provides faster respiratory recovery.

In conclusion, both midazolam + alfentanil and propofol sedation regimens appear to be suitable for FFB. The present study shows that sedation with propofol for FFB is safe when administered in small boluses at short intervals by trained personnel, and the respiratory status is well monitored during the procedure. These findings regarding the safety of propofol are important in light of earlier studies showing that sedation with propofol can achieve satisfactory sedation for FFB, with shorter recovery time and greater patient satisfaction [8].

\section{Financial Disclosure and Conflicts of Interest}

The authors have no conflict of interest to declare. No funding was received for this study.

\section{References}

1 Stolz D, Chhajed PN, Leuppi JD, Brutsche M, Pflimlin E, Tamm M: Cough suppression during flexible bronchoscopy using combined sedation with midazolam and hydrocodone: a randomised, double blind, placebo controlled trial. Thorax 2004;59:773-776.

$\checkmark 2$ British Thoracic Society Bronchoscopy Guidelines Committee: British Thoracic Society guidelines on diagnostic flexible bronchoscopy. Thorax 2001;56(suppl 1):i1-i21.

3 Ereth MH, Stubbs SE, Lennon RL: Bronchoscopic pharmacology and anesthesia; in Prakash UBS (ed): Bronchoscopy. New York, Raven Press, 1994, p 91.
4 Shelley MP, Wilson P, Norman J: Sedation for fiberoptic bronchoscopy. Thorax 1989; 44:311-317.

5 Bosslet G, DeVito M, Lahm T, Sheski F, Mathur P: Nurse-administered propofol sedation: feasibility and safety in bronchoscopy. Respiration 2010;79:315-321.

6 Barash PG, Cullen BF, Stoelting RK: Clinical Anesthesia, ed 6. Philadelphia, Lippincott Williams \& Wilkins, 2009, pp 451-452.

7 Dreher M, Ekkernkamp E, Hendrik J, Hans J, Kabitz J, Windisch W: Sedation during flexible bronchoscopy in patients with preexisting respiratory failure: midazolam versus midazolam plus alfentanil. Respiration 2010;79:307-314.
8 Crawford M, Pollock J, Anderson K, Galvin RJ, MacIntyre D, Vernon D: Comparison of midazolam with propofol for sedation in outpatient bronchoscopy. Br J Anaesth 1993; 70:419-422.

-9 Clarkson K, Power CK, O’Connell F, Pathmakanthan S, Burke CM: A comparative evaluation of propofol and midazolam as sedative agent in fiberoptic bronchoscopy. Chest 1993;104:1029-1031.

10 Clark G, Licker M, Younossian AB, et al: Titrated sedation with propofol or midazolam for flexible bronchoscopy: a randomised trial. Eur Respir J 2009;34:1277-1283. 
11 Evans EN, Ganeshalingam K, Ebden P: Changes in oxygen saturation and transcutaneous carbon dioxide and oxygen levels in patients undergoing fibreoptic bronchoscopy. Respir Med 1998;92:739-742.

12 Fu ES, Downs JB, Schweiger JW, Miguel RV, Smith RA: Supplemental oxygen impairs detection of hypoventilation by pulse oximetry. Chest 2004;126:1552-1558.

13 Chhajed PN, Glanville AR: Management of hypoxemia during flexible bronchoscopy. Clin Chest Med 2003;24:511-516.

$\checkmark 14$ Chhajed PN, Heuss LT, Tamm M: Cutaneous carbon dioxide tension monitoring in adults. Curr Opin Anaesthesiol 2004;17:521-525.

$\checkmark 15$ Kocher S, Rohling R, Tschupp A: Performance of a digital $\mathrm{PCO}_{2} / \mathrm{SPO}_{2}$ ear sensor. J Clin Monit Comput 2004;18:75-79.

16 Chhajed PN, Langewitz W, Tamm M: (Un) explained hyperventilation. Respiration 2005;73:825.
17 Chhajed PN, Kaegi B, Rajasekaran R, Tamm $\mathrm{M}$ : Detection of hypoventilation during thoracoscopy: combined cutaneous carbon dioxide tension and oximetry monitoring with a new digital sensor. Chest 2005;127:585588.

18 Stege G, Van den Elshout F, Heijdra Y, Van de Ven M, Dekhuijzen R, Vos P: Accuracy of transcutaneous carbon dioxide tension measurements during cardiopulmonary exercise testing. Respiration 2009;78:147-153.

19 Heuss LT, Chhajed PN, Schnieper P, Hirt T, Beglinger C: Combined pulse oximetry/cutaneous carbon dioxide tension monitoring during colonoscopies: pilot study with a smart ear clip. Digestion 2004;70:152-158.

20 Chhajed PN, Rajasekaran R, Kaegi B, et al: Measurement of combined oximetry and $\mathrm{cu}$ taneous capnography during flexible bronchoscopy. Eur Respir J 2006;28:386-390.

21 Shelley MP, Wilson P, Norman J: Sedation for fiberoptic bronchoscopy. Thorax 1989; 44:769-775.
22 Lundgren R, Haggmark S, Reiz S: Hemodynamic effects of flexible fiberoptic bronchoscopy performed under local anesthesia. Chest 1982;82:295-299.

23 Putinati S, Ballerin L, Corbetta L, Trevisani L, Potena A: Patient satisfaction with conscious sedation for bronchoscopy. Chest 1999;115:1437-1440.

24 Matot I, Kuras Y Kramer MR: Effect of clonidine premedication on hemodynamic response to fiberoptic bronchoscopy. Anaesthesia 2000;55:269-274.

25 Fox B, Krylov Y, Leon P, et al: Benzodiazepine and opioid sedation attenuate the sympathetic response to fiberoptic bronchoscopy. Prophylactic labetalol gave no additional benefit. Result of a randomized double-blind placebo-controlled study. Respir Med 2008; 102:978-983.

\section{Erratum}

The authors of the article 'Anemia of Chronic Disease in Chronic Obstructive Pulmonary Disease: A Case-Control Study of Cardiopulmonary Exercise Responses', published in Respiration 2011;82:237-245, wish to correct the following error on page 238, in the Material and Methods section, first paragraph of Study Population, in the 5th line: the phrase 'December 2009' should be replaced by 'June 2009'.

The correct sentence should read as follows:

'The relevant population consisted of consecutive, clinically stable patients with COPD who visited the Respiratory Failure Unit and the Pulmonary Clinic of the 'G. Papanikolaou' Hospital (Thessaloniki, Greece) as outpatients between June 2009 and May 2010. 